IAC-06-A1.1.4

\title{
PATTERNS IN CREW-INITIATED PHOTOGRAPHY OF EARTH FROM ISS-IS EARTH OBSERVATION A SALUTOGENIC EXPERIENCE?
}

\author{
Julie A. Robinson ${ }^{1}$, Kelley J. Slack ${ }^{2}$, Valerie Olson ${ }^{3}$, Mike Trenchard $^{4}$, Kim Willis $^{4}$, Pam Baskin ${ }^{2}$,
} Jennifer Boyd Ritsher ${ }^{5}$

${ }^{1}$ Office of the ISS Program Scientist, NASA Johnson Space Center, Houston, TX, USA, julie.a.robinson@nasa.gov; ${ }^{2}$ Wyle Laboratories, Houston, TX, USA; ${ }^{3}$ National Space and Biomedical Research Institute, Houston, TX, USA; ${ }^{4}$ Image Science \& Analysis Laboratory, ESCG, Johnson Space Center, Houston, TX, USA; ${ }^{5}$ University of California and Veterans Affairs Medical Center, San Francisco, CA, USA

\begin{abstract}
Background: To provide for crewmember well-being on future exploration missions, understanding coping strategies that International Space Station (ISS) crewmembers adopt to mitigate the inherent stress of long-duration confinement is important. A recent survey of flown astronauts found that the most commonly reported psychologically enriching aspects of spaceflight involved their "Perceptions of Earth." ISS crewmembers photograph Earth volitionally and in response to requests from Crew Earth Observations (CEO) scientists. Our study used objective in-flight data generated by self-initiated photography to investigate the nature of voluntary activity. Results: Of nearly 200,000 photographs taken on eight ISS expeditions, $84.5 \%$ were crew-initiated. Once a crewmember went to the window for a CEO request, they were more likely to take photographs for their own interest. Fewer self-initiated images were taken during, and immediately preceding, major station events. Crewmembers were more likely to take self-initiated images during periods of greater availability. Analysis indicated some phasing in patterns of photography during the course of a mission, although no third quarter effect was found. Discussion: Earth photography offers self-initiated positive activity of possible importance for salutogenesis (maintenance of well-being) of astronauts on long-duration missions. Scientific requests for photography through CEO play an important role in facilitating crew-initiated photography.
\end{abstract}

\section{BACKGROUND}

\section{Introduction}

While NASA has always engaged in space exploration research, The Vision for Space Exploration [1] and subsequent definition of specific exploration mission architectures have required a much more focused use of the International Space Station (ISS). In particular, the ISS is to be used for research on human health or long-duration space missions as well as technology development and testing [1,2].
Behavioral Health and Performance has been identified as a discipline with additional research needs requiring the ISS $[3,4]$. Maximizing psychological well-being and performance of the crew while in a confined space with limited interpersonal interactions is important for the success of ongoing ISS missions. Knowledge about behavioral health gained from ISS missions is also important for the success of future missions to a lunar base, and provides key data for a 4- to 6 month Mars transit. A particular concern is maintaining crew psychological well-

*This is a work of the U.S. Government and is not subiect to copvright protection in the United States. 
being for the duration of a round-trip mission to Mars which could last as long as three years [3].

Positive (or "salutogenic") experiences while in space may promote psychological well-being by enhancing personal growth and may be important for offsetting the challenges of living and working in a confined and isolated environment $[5,6]$. In a survey of flown astronauts aimed at identifying the positive or salutogenic effects of spaceflight, Ihle et al. [7] identified positive changes in the "Perceptions of Earth" as the most important change experienced by astronauts. If viewing Earth is an important component of positive experiences in spaceflight, then the "Earth-out-of-view" may be an important challenge for crews going to Mars, increasing the sense of isolation [8]. To the extent that observing the Earth is a positive experience for ISS crewmembers, replacement activities or new psychological countermeasures may be needed to insure the well-being of crewmembers on a Mars mission.

In addition to watching the Earth, ISS crewmembers photograph the Earth through the windows of ISS, and are able to share those images with the world (e.g. [9]). The Crew Earth Observations (CEO) activity provides a venue to transmit requests for photographs of areas of scientific or public interest to the astronauts each day, and to distribute the acquired photographs to scientists and the public. Crewmembers take photographs of the targets on a time available basis. Further, crewmembers can choose to take additional images of Earth that have been requested by CEO. These self-initiated images would seem to be of special importance to crewmembers since the taking of these images is purely volitional. Whether requested by scientists or self-initiated, images of Earth taken from ISS are identified and distributed via the "Gateway to Astronaut Photography of Earth" website [10].

In this paper, we mine the dataset of Earth observation photography to see whether additional information could be gleaned about the importance of viewing the Earth as a positive experience for the crewmember. Our first objective was to quantify the extent to which photography of Earth was self-initiated. A second objective was to identify patterns in photography, or conditions under which crewmembers were more likely to take selfinitiated images. From this we hoped to gain quantitative (although correlative) insight into whether Earth observation activities play a role in maintaining the psychological well-being of longduration crewmembers on ISS.

\section{Hypotheses}

Prior to analyzing the photographic incidence data, we generated the following hypotheses:

Hypothesis 1: Fewer self-initiated images are expected to be taken during periods of, and preparation for, extraordinary activities. Daily activities on station can be very crudely dichotomized into regular daily activities and extraordinary activities. Extraordinary activities include extra-vehicular activity (EVA; i.e., spacewalk), during docking and undocking (i.e., of Space Shuttle, Soyuz, and Progress spacecraft). Further these extraordinary activities require substantial focus and preparation leading up to the event. Extraordinary activities generally consume more time than regular daily activities leaving less time for volitional activities, such as taking images.

Hypothesis 2: More self-initiated images are expected to be taken during weekends. Typically crewmembers have fewer set tasks to accomplish on weekends, giving them increased periods of time in which they can choose their activities. Given the volitional nature of selfinitiated images coupled with the enjoyment crews have stated that they receive from viewing Earth (Ihle, et al., 2006), we expected crewmembers to take more Earth photographs during periods of decreased workload.

Hypothesis 3: More self-initiated images are expected to be taken of geographic areas of personal interest to crewmembers. Past crews have placed great importance on viewing Earth (Ihle, et al., 2006). Following on from that, the viewing of places that hold special meaning for crewmembers, such as their childhood home or their alma mater, might be expected to be of particular importance. 
Hypothesis 4a: Phasing occurs such that differing numbers of self-initiated images are taken over the course of a mission. Hypothesis 4b: During the third quarter of the mission, increased numbers of self-initiated images are taken. Previous research, both in space and in analogue environments such as the Antarctic (e.g., [11, 12, 13, 14, 15], has found mixed results regarding the existence of either phasing or a third quarter effect. The term phasing suggests that isolated individuals experience a cycle of ups and downs in psychological well-being during their time in confinement. While the term phasing is more general, the term third quarter effect specifically refers to a period of lowered psychological wellbeing during the third quarter of an extended confinement. Thus, we looked for several possible temporal patterns in the incidence of self-initiated photography.

\section{METHODS}

\section{Participants}

Images from a total of 19 ISS crewmembers beginning with ISS Expedition 4 (December 2001, when the full capability to the digital camera began to be used) and continuing through Expedition 11 (October 2005) were included in this study. Ten were astronauts with NASA and nine were Russian cosmonauts. The expeditions consisted of three crewmembers through Expedition 6 when the number of crewmembers on station dropped to two, one Russian and one American. Gender of the crew for Expeditions 4 through 11 was predominately male with only one female astronaut. It is not known whether every individual on board ISS actually used the camera, nor which individuals took which images.

\section{Data and Analyses}

Digital photographs are taken on orbit and downlinked to the ground during the course of the mission. These are separated by content (Earth, hardware, people). All Earth images become part of the Database of Astronaut Photography of Earth, which was used for these analyses.
We analyzed the Earth photography patterns using the digital data recorded on the back of the digital cameras used on ISS. The cameras automatically record date and time the photograph was taken, as well as specific photographic parameters. The data do not identify the individuals using the camera, as any crewmember may pick up any camera to take pictures, and individuals often stop briefly at a window to take pictures throughout the day.

Additional datasets compiled for use in analyses were (1) lists of areas of known geographic interest to crews based on publicly released biographical information (2) orbital track parameters to relate images taken to the log of scientific requests sent to the crew and (3) records of on-orbit activities to determine the incidence of EVAs, docking of visiting vehicles, and days of light duty/holidays. We used the orbit tracks and message logs to identify which photographs were in response to CEO requests, and which were self-initiated by the crew. Camera timestamps were also screened for inaccuracies when the date needed to be reset, and these records were eliminated from the analyses.

For each day, we determined the number of images of Earth that were self-initiated, were of areas of known geographic interest to any member of that crew, were in response to a scientific request, and used the $800 \mathrm{~mm}$ lens (high magnification) lens setup. The use of the $800 \mathrm{~mm}$ lens was tracked because it represents a significant skill that requires much effort to achieve the best results, and the resulting images provide the most detail (up to $6 \mathrm{~m}$ spatial resolution). The crew members must practice tracking the motion of the Earth beneath the ISS using the camera equipped with the $800 \mathrm{~mm}$ lens, and learn how to properly focus through the lens [9].

Hypotheses 1 and 2 were addressed by examining zero order correlations, and using general linear models using the GLIMMIX procedure in SAS. This procedure fits generalized linear mixed models to the data and allows for normally distributed (Gaussian) random effects [16]. Hypothesis 3 was tested using a related 
procedure, GENMOD. Hypothesis 4a was tested using regression, while general linear model repeated measures analysis was used for Hypothesis $4 b$. take self-initiated images of geographic areas of Earth that were of personal interest to them $(r=.25, p<.01)$. A crew containing a member, for example, whose childhood home was in a small town in Illinois, would be more likely to take images of that area than of areas not holding

\begin{tabular}{|c|c|c|c|c|c|c|c|c|c|}
\hline & & Mean & Std Dev & 1 & 2 & 3 & 4 & 5 & 6 \\
\hline \multicolumn{10}{|c|}{ Daily number of: } \\
\hline 1 & Total images taken & 102.3 & 119.1 & -- & & & & & \\
\hline 2 & Self-initiated images taken & 86.4 & 107.5 & $.98^{\star \star}$ & -- & & & & \\
\hline 3 & Images of geographic interest & 1.6 & 5.1 & $.25^{\star \star}$ & $.25^{\star \star}$ & -- & & & \\
\hline 4 & Requested images taken & 15.9 & 25.3 & $.54^{\star \star}$ & $.36^{\star \star}$ & $.10^{\star *}$ & -- & & \\
\hline 5 & Images taken with $800 \mathrm{~mm}$ & 17.8 & 34.4 & $.41^{\star *}$ & $.41^{\star *}$ & $.15^{\star \star}$ & $.19^{\star \star}$ & -- & \\
\hline \multicolumn{10}{|c|}{ Proportion of days: } \\
\hline 6 & Higher availability to take images & .3 & .4 & $.06^{*}$ & $.07 * \star$ & -.01 & -.03 & $.07^{\star \star}$ & -- \\
\hline
\end{tabular}

Table 1. Means, standard deviations, and correlations across all missions. Each parameter is measured on a daily basis across all expeditions combined. ** Correlation is significant at the 0.01 level (2-tailed). * Correlation is significant at the 0.05 level (2-tailed).

\section{RESULTS}

From December 2001 (Expedition 4) through October 2005 (Expedition 11) crewmembers took 144,180 images that had accurate time and date data automatically recorded by the camera. Of time-stamped photographs, $84.5 \%$ were crewinitiated, and not in response to $\mathrm{CEO}$ requests.

\section{Zero-Order Correlations}

Correlations along with means and standard deviations are detailed in Table 1 for all measures included in the study. For subsequent analyses, we considered only self-initiated images and excluded images in response to CEO requests.

Self-initiated images were related to requested images $(r=.36, p<.01)$. A crewmember with a camera in his/her hands was more likely to take self-initiated photos in addition to the requested images. Further, taking self-initiated images was related to images taken at $800 \mathrm{~mm}$ focal length $(r=.41, p<.01)$. Although taking images at $800 \mathrm{~mm}$ was more challenging, it was the focal length more frequently chosen when crewmembers took images of their own choice. Further, crewmembers were also more likely to personal significance for any members of that crew.

Weekend was related to self-initiated images $(r=.07, p<.01)$ such that crews were more likely to take self-initiated images on weekends. Contrary to expectations, neither activity nor holiday was related to self-initiated images. Due to space limitations, weekend, activity, and holiday are not included in Table 1. However, when holiday, weekend, and activity were compiled into a measure of general availability to take images, then this general availability was related to self-initiated images $(r=.07, p<.01)$. The direction of this effect indicates that crewmembers were more likely to take selfinitiated images when they had time available.

\section{Hypotheses}

Hypothesis 1: Activity. Hypothesis 1 stated that fewer self-initiated images would be taken one week prior to and during extraordinary mission events, such as EVAs and dockings. Conditional upon the random effect of the intercept and controlling for time (days) on station, type of activity on station predicted whether self-initiated images were taken $(t=-2.50, \quad p<.01)$. Crewmembers were less likely to take selfinitiated images while preparing for and during 
these mission events than during regular daily station activities. Further, activity predicted differentially across time $(t=-4.65, p<.01)$, such that crewmembers were more likely to take selfinitiated images on days of regular station activities as the mission progressed (Fig. 1).

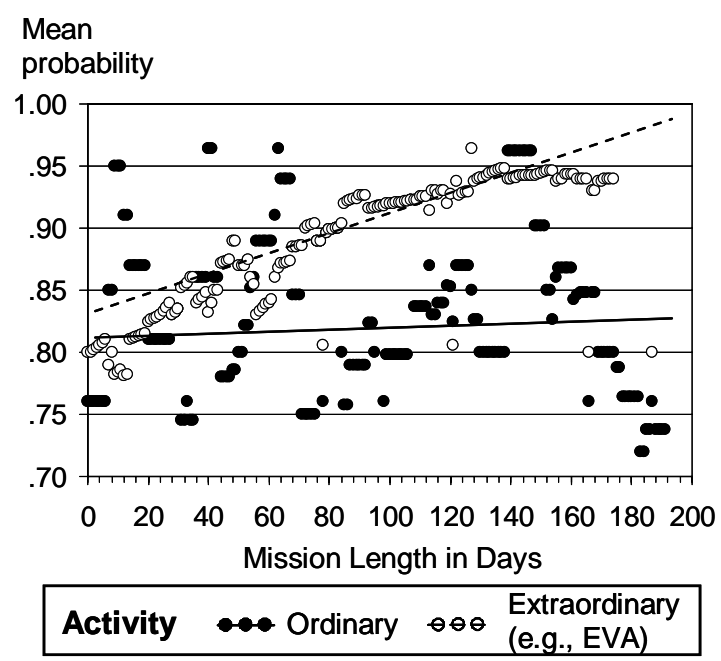

Fig. 1: Probability that Self-Initiated Images Were Taken-Using Activity as a Predictor across Mission

General activity did not predict the number of self-initiated images taken during regular or extraordinary mission events $(t=-.77$, ns). Thus, while there was a difference between types of days with regard to whether or not any selfinitiated images were taken, there was no discernable difference in the number of images taken either on a particular day or as the mission progressed.

Hypotheses 2: Weekends. According to Hypothesis 2, more self-initiated images would be taken on weekends. This hypothesis was not supported $(t=.65, \mathrm{~ns})$, perhaps because life on station does not always allow weekends off.

In response to this supposition, a composite variable of days available, or general availability, was created to more accurately reflect workload on station. This composite took into account whether activity on station was extraordinary or not, whether it was a weekend, and whether a particular day was considered an off or partial duty day or a regular duty day. General availability was thus a more realistic representation of days with crewmember free time.

This post hoc hypothesis was supported. General availability was associated with whether selfinitiated images were taken $(t=4.37, p<.01)$, conditional upon the intercept and after controlling for time on station. Not surprisingly, more self-initiated images were taken when crewmember schedules allowed (Fig. 2). Crewmembers were less likely to take selfinitiated images on a Saturday, for example, if they were also preparing for an EVA. Additionally, general availability predicted differentially as the mission progressed $(t=2.26$, $p=.02$ ) such that crewmembers became even more likely to take self-initiated images when their schedules allowed later in the mission.

General availability also predicted the number of self-initiated images taken $(t=2.10, p=.02)$ after controlling for the intercept and time on station. General availability did not, however, differentially predict over the length of the mission $(t=-1.22$, ns). In other words, general availability predicted the same way across the entire mission.

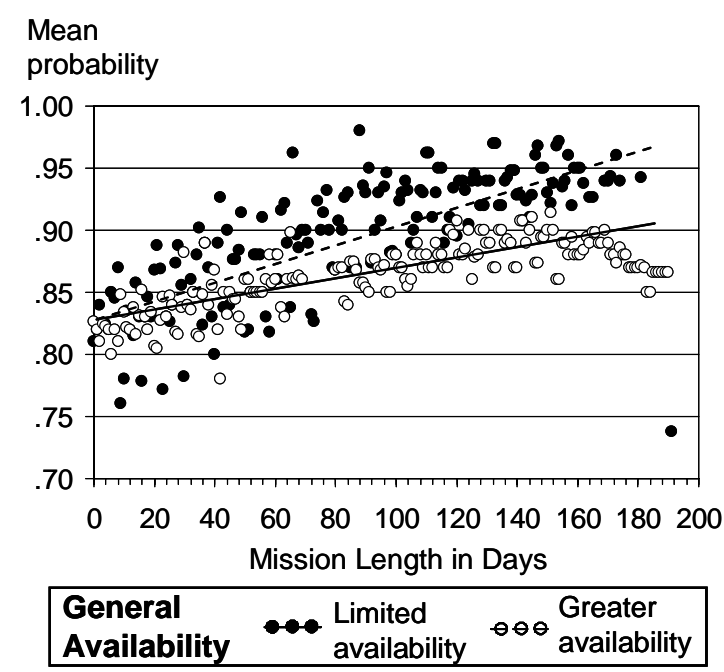

Fig. 2: Probability that Self-Initiated Images Were Taken-Using General Availability as a Predictor across Mission

Hypothesis 3: Geographic Interest. Hypothesis 3 stated that crewmembers would take more selfinitiated images of areas that were of personal 
interest to them. Due to limitations in the GLIMMIX procedure, a model fitting geographic interest could not converge. As an alternative, the GENMOD procedure was used. Given that GLIMMIX uses the GENMOD procedure to fit generalized linear models when random effects are absent [16], this change in statistical procedure is not significant.

This hypothesis was not supported by the data $\left(\chi^{2}(\mathrm{df}=1)=1.14, \mathrm{~ns}\right)$. Crewmembers were no more likely to take self-initiated images of geographic areas of personal interest to them than they were to take any other self-initiated images. The fidelity of the measure of areas of personal interest is questionable though. The geographic areas of interest were determined by the researchers rather than by crewmembers themselves.

Hypothesis 4: Phasing/Third Quarter Effects. Hypothesis 4a stated that phasing would occur such that self-initiated images would be taken differentially across the mission. Regression was used to assess curvilinearity in the data. The quadratic term was significant $\left(R^{2}=.02, p<.01\right)$. Thus, this hypothesis was supported in that the number of self-initiated images taken is not consistent across the duration of the mission. Hypothesis 1 lends further support to Hypothesis $4 \mathrm{a}$. When using type of activity as a predictor, time on station was a significant predictor of whether self-initiated images would be taken $(t=3.16, p<.01)$. Conditional upon type of activity, the longer the crewmembers were on station, the more likely they were to take selfinitiated images.

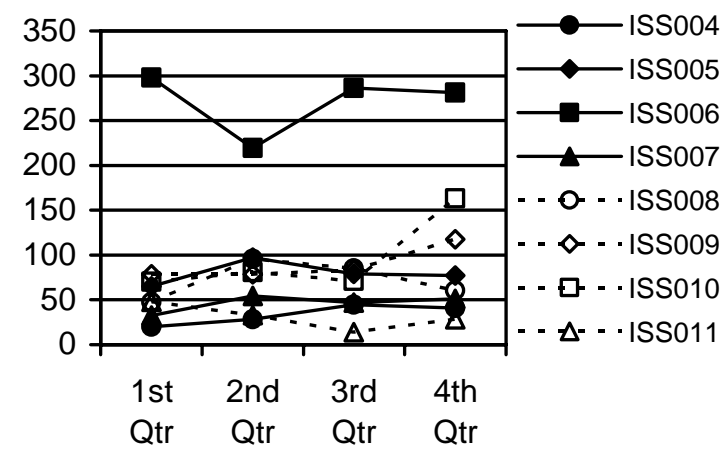

Fig. 3: Quarterly Estimated Marginal Mean Number of Self-Initiated Images Taken by Miccinn
Hypothesis $4 \mathrm{~b}$ stated that greater numbers of selfinitiated images would be taken during the third quarter of the mission. Using general linear model repeated measures, this hypothesis was not supported. Figure 3 effectively illustrates the lack of a third quarter effect.

\section{DISCUSSION}

In this study we made novel use of data available on the patterns of Earth photography by crews aboard the International Space Station. Although by its nature the data are observational, they allow additional insights into the role that observing Earth plays in the daily lives of crews in orbit. Perhaps the most important observation is the importance that photography of Earth has for at least some crewmembers, as evidenced by the degree to which it is self-initiated $(84.5 \%$ of 144,180 photographs), and conducted as a leisure activity (e.g., Fig 4). As of mid-2006, active photography of Earth has continued with a total over 250,000 images through Expedition 13.

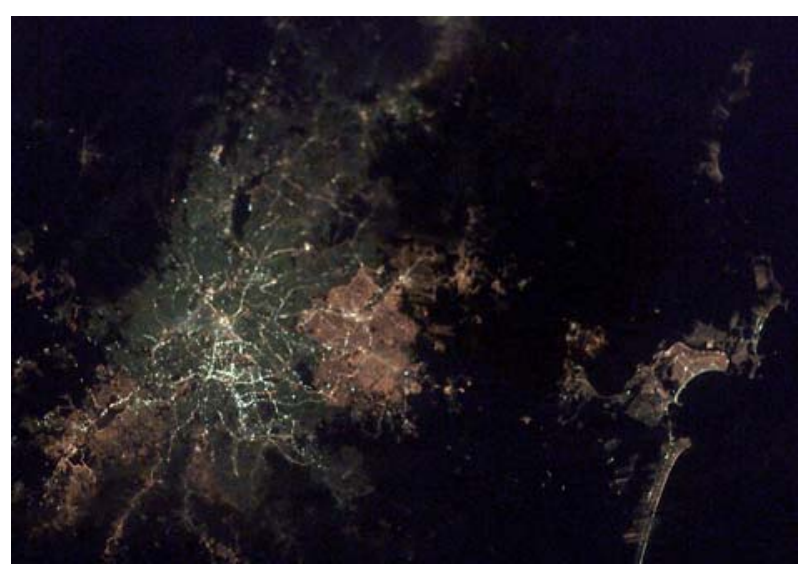

Fig. 4: Example of a Crew-initiated Image of São Paulo, Brazil, at Night. While staying on ISS, Astronaut Don Pettit assembled a homemade tracking system to photograph long-exposure images under low light conditions. (ISS006-E44689, April 12, 2003),

Earth photography offers several venues for personal accomplishments for ISS crew members. For example, the use of motion tracking with the $800 \mathrm{~mm}$ lens combination to achieve high-quality, high-magnification images of Earth is a challenge that some crewmembers have relished. Anecdotally, some crewmembers do not try to use the combination, others make it a personal challenge, and several crewmembers have become expert at its use, taking many 
thousands of such images during their mission (e.g., Fig. 5). We cannot distinguish whether the most important element of this activity is taking and sharing these sometimes astounding images of Earth, the challenge of learning/perfecting a new skill, or a combination (e.g., Fig. 6).

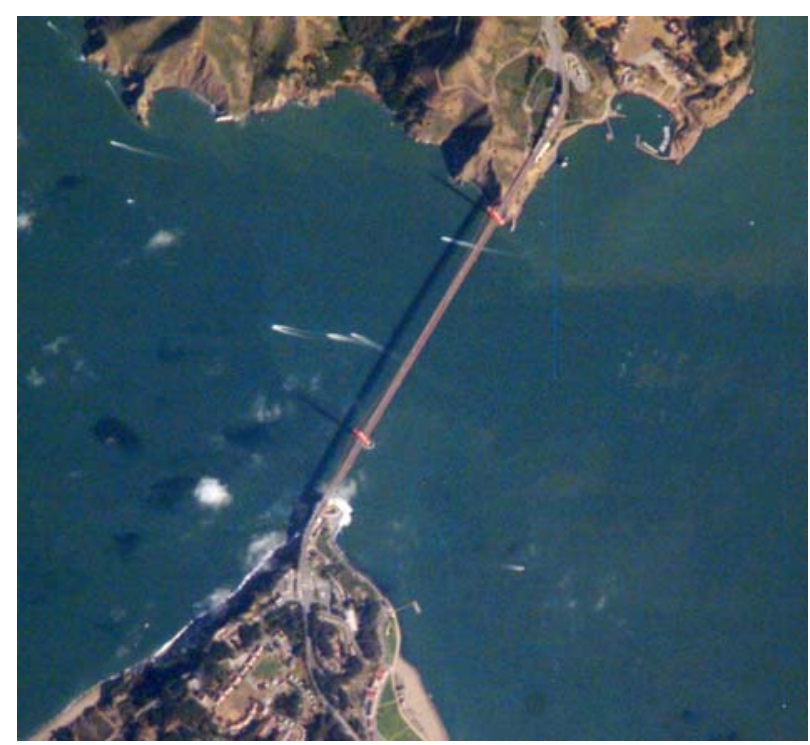

Fig. 5: Example of a Crew-Initiated Image Using the $800-\mathrm{mm}$ Lens Combination. This shows a portion of an image of the Golden Gate Bridge, San Francisco, California, taken by Astronaut Jeff Williams from ISS during Expedition 13. With his crewmates, Williams holds the record for the largest number of Earth images taken during an expedition (over 62,000 with several weeks to go before the end of the expedition, ISS013-E-65111, August 6, 2006).

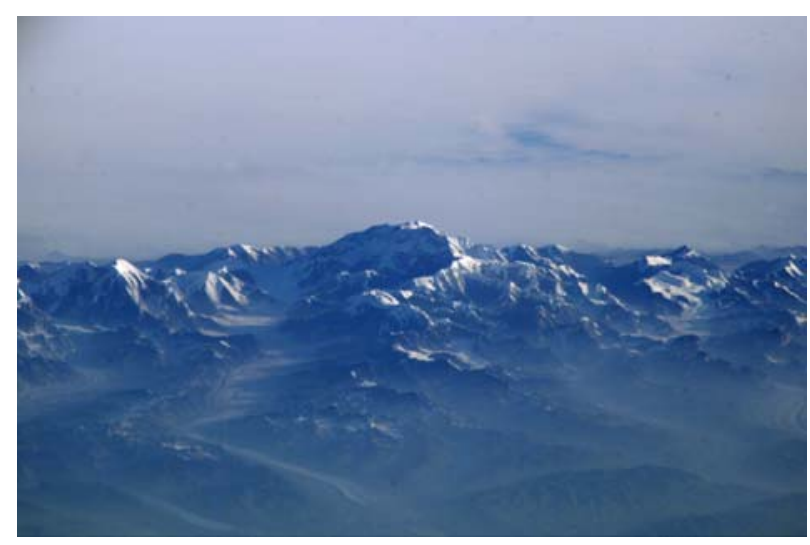

Fig. 6: View of Mt. McKinley (Denali), Alaska, taken from ISS using a powerful 800-millimeter lens to photograph this peak while the spacecraft was over the Gulf of Alaska, 800 miles to the south of the mountain. Cosmonaut Sergei Krikalev has assembled a collection of these views of major world mountain peaks during his stays on ISS during Expeditions 1 and 11 (ISS011-E-11806, August 14, 2005).

The correlation between scientific requests and self-initiated photography might reflect the practicality of a crewmember continuing to photograph Earth once he/she has a camera in hand. However, it is also suggestive of the importance of the scientific basis and public use of photographs in making the activity worthwhile for the crews. The scientific support from Crew Earth Observations enables self-initiated photography of Earth, by providing opportunities and reminders to go to the window with a camera. It is likely that the image identification and web distribution completed by CEO adds value to the self-initiated photography by insuring that it can be shared with the world-but this would required a more structured survey of crewmembers to confirm.

From our analyses for Hypotheses 1 and 2, selfinitiated images were less likely to be taken when workload prevented it-Earth photography is clearly a leisure activity. However crews are more likely to take self-initiated images as mission progresses; perhaps due to acclimation and familiarity with life and duties on station or a growing realization that their time in space, and thus their ability to photograph Earth from space, is limited. This trend over the duration of the mission was the only mission phasing observed. A more careful examination of Figure 3, suggests that the phasing effect might be due more to individual differences pertaining to specific missions. It is not clear the extent to which this might reflect differences in mission profiles or characteristics of the particular crewmembers assigned to the particular missions.

\section{Future Research and Applications}

In spite of the importance of behavioral health and performance for the success of human spaceflight missions, relatively few studies have been done on ISS to date $[17,18]$. This analysis of data collected for other purposes serves as an example of mining data collected as part of ISS operations to increase knowledge. Such analyses can inform surveys for future data collection, and 
influence future behavioral studies on ISS. Given these observations, future studies should consider crew motivations in photographing the Earth. Psychological component testing could reveal whether taking more self-initiated images is associated with increased crew psychological well-being.

The importance of viewing Earth reported in crew surveys [7], and the patterns in photography of Earth reported in our analysis, suggest that the positive psychological role from these activities is important. Conclusions from this type of correlative data mining are only suggestive of the importance of Earth observation for crewmembers. Future studies of behavioral health should consider quantitative assessment of salutogenic effects of leisure activities such as Earth observations.

As we begin to plan for interplanetary missions, it is important to consider what types of activities could be substituted. Perhaps the crew members best-suited to a Mars transit are those individuals who can get a boost to psychological well-being from scientific observations and astronomical imaging. Replacements for the challenge of mastering the $800-\mathrm{mm}$ photography could also be identified. As humans head beyond low Earth orbit, crewmembers looking at Earth will only see a "pale blue dot," and then someday in the far future be too far away to view the Earth at all.

\section{ACKNOWLEDGEMENTS}

We would like to thank Edna Fiedler and Frank Carpenter for encouragement to pursue these analyses. Chuck Green advised us on the statistical analyses, and helped with access to SAS procedures. We also thank Cindy Evans, Edna Fiedler and Nick Kanas for their reviews and suggestions for improvement.

\section{REFERENCES}

1 National Aeronautics and Space Administration (2004) The Vision for Space Exploration, NP2004-01-334-HQ, NASA Headquarters, Washington, DC.

2 National Aeronautics and Space Administration (2006) The NASA Research and Utilization Plan for the International Space Station (ISS), A Report to the Committee on Science of the United States House of Representatives and the Committee on Commerce, Science, and Transportation of the
United States Senate, NASA Headquarters, Washington, DC.

3 National Aeronautics and Space Administration (2005) Bioastronautics Roadmap: A Risk Reduction Strategy for Human Space Exploration, NASA/SP-2004-6113, NASA Johnson Space Center, Houston, Texas.

4 Ball, J.R., Evans, C.H., Jr., Eds. Safe Passage: Astronaut Care for Exploration Missions. Committee on Creating a Vision for Space Medicine During Travel Beyond Earth Orbit, Board on Health Sciences Policy, National Institute of Medicine, National Academy Press, Washington, DC.

5 Suedfeld, P. (2001) Applying positive psychology in the study of extreme environments. Journal of Human Performance in Extreme Environments, 6:21-25.

6 Suedfeld, P., Weiszbeck, T. (2004) The impact of outer space on inner space. Aviation, Space, and Environmental Medicine 75(7, Suppl.):C6-9.

7 Ihle, E. C., Ritsher, J. B., Kanas, N. (2006) Positive psychological outcomes of spaceflight: An empirical study. Aviation, Space, and Environmental Medicine, 77, 93-101.

8 Kanas, N., Manzey, D. (2003) Space psychology and psychiatry. Dordrecht: Kluwer Academic Publ..

9 Robinson JA, Evans CA (2002) Space Station Allows Remote Sensing of Earth to within Six Meters. Eos, Transactions of the American Geophysical Union, 83:185-188.

10 "Gateway to Astronaut Photography of Earth Website," NASA, http://eol.jsc.nasa.gov .

11 Bechtel, R. B., Berning, A. (1991). The thirdquarter phenomenon: Do people experience discomfort after stress has passed? In A. A. Harrison, Y. A. Clearwater, \& C. P. McKay (Eds.), From Antarctica to Outer Space: Life in Isolation and Confinement. Springer Verlag, New York, pp. 261-266.

12 Connors, M. M., Harrison, A. A., Akins, F. R. (1985) Living Aloft: Human Requirements for Extended Spaceflight. Washington, DC: National Aeronautic and Space Administration.

13 Kanas, N., Weiss, D. S., Marmar, C. R. (1996) Crew member interactions during a Mir space station simulation. Aviation, Space, and Environmental Medicine, 67, 969-975.

14 Sandal, G. M. (2000). Coping in Antarctica: Is it possible to generalize results across settings? Aviation, Space and Environmental Medicine. 71(9, Suppl.), A37-A43. 
15 Stuster, J., Bachelard, C., Suedfeld, P. (2000). The relative importance of behavioral issues during long-duration ICE missions. Aviation, Space, and Environmental Medicine, 71(9, Suppl.), A17-A25.

16 SAS (November, 2005). The GLIMMIX procedure.

http://support.sas.com/rnd/app/papers/glimmix.pdf

17 Rhatigan JL, Robinson JA, Sawin, CF. (2005) Exploration - Related Research on ISS: Connecting Science Results to Future Missions. 44th AIAA Aerospace Sciences Meeting,;AIAA 2006-344 (Also publ. as NASA/TP 2005-213166).

18 Robinson, J.A., Rhatigan, J.L., Baumann, D.K., Tate, J., Thumm, T. (2006) International Space Station Research Summary through Expedition 10. NASA/TP 2006-213146. Lyndon B. Johnson Space Center, Houston, Texas, 126 pp. 